\title{
Is left-sided involvement of hepatocellular carcinoma an important preoperative predictive factor of poor outcome?
}

\author{
Yuhki Sakuraoka* ${ }^{*}$, Keiichi Kubota, Genki Tanaka, Takayuki Shimizu, Kazuma Tago, Kyung Hwa Park, \\ Takatsugu Matsumoto, Takayuki Shiraki, Shozo Mori, Yukihiro Iso and Taku Aoki
}

\begin{abstract}
Background: The tumor location is the most simple clinical factor and important in liver surgery to make surgical procedure. However, no previous study has investigated the prognostic differences and clinical features of hepatocellular carcinoma showing specific laterality. This study is the first report to focus on the laterality and aimed to lead to more simple and useful predictive factor rather than recent complicated predictive models.

Methods: Patients who underwent liver resection for the first time for single tumors located within each lobe between 2000 and 2018 were enrolled. We divided them into two groups based on tumor location: a right-sided group and a left-sided group. Univariable and multivariable analyses were performed to assess survival differences in relation to several other factors.

Results: There were 595 eligible patients; the 5-year survival rates and disease-free survival rates were $49.5 \%$ and $19.1 \%$ in the left-sided group and $55.6 \%$ and $24.5 \%$ in the right-sided group, respectively $(p=0.026)$. Statistical analyses revealed that the following preoperative prognostic factors were independently significant $(p<0.05)$ in the left-sided group: indocyanine green retention rate at $15 \mathrm{~min}$, alpha fetoprotein, protein induced by vitamin $\mathrm{K}$ absence or antagonists-ll level, and larger tumor size.

Conclusion: The left-sided group had a poorer prognosis than the right-sided group. A left-sided tumor location is a significant preoperative factor predictive of poor outcome in patients with hepatocellular carcinoma.
\end{abstract}

Keywords: Hepatocellular carcinoma, Liver surgery

\section{Background}

Recently, there have been several types of predictive factors in liver surgery. Some of them are complicated and difficult to perform in daily clinical settings. We explored more simple predictive factors in order to easier project the patient outcomes. In this study, we focused on the tumor location. This is because it is easy and simple to detect. Although the tumor location is important in liver surgery to make surgical procedure, no previous

\footnotetext{
*Correspondence: sakuraoka812@gmail.com

Second Department of Surgery, Dokkyo Medical University, 880 Kitakobayashi, Mibu, Tochigi 321-0293, Japan
}

study has investigated the prognostic differences and clinical features of hepatocellular carcinoma (HCC) showing specific laterality.

In general, the organs located on the left and right sides of the body show some specific anatomical features. For instance, the right lung has three lobes, whereas the left lung consists of two lobes. Moreover, the hemispheres of the brain show unique differences in terms of function. The right lobe of the liver is divided into four segments, while the left lobe consists of three segments $[1,2]$. Previous studies have revealed that there are also some differences in the malignant characteristics

C C The Author(s). 2020 Open Access This article is licensed under a Creative Commons Attribution 4.0 International License, which permits use, sharing, adaptation, distribution and reproduction in any medium or format, as long as you give appropriate credit to the original author(s) and the source, provide a link to the Creative Commons licence, and indicate if changes were made. The images or other third party material in this article are included in the article's Creative Commons licence, unless indicated otherwise in a credit line to the material. If material is not included in the article's Creative Commons licence and your intended use is not permitted by statutory regulation or exceeds the permitted use, you will need to obtain permission directly from the copyright holder. To view a copy of this licence, visit http://creativecommons.org/licenses/by/4.0/ The Creative Commons Public Domain Dedication waiver (http://creativecommons.org/publicdomain/zero/1.0/) applies to the data made available in this article, unless otherwise stated in a credit line to the data. 
and prognosis of tumors located in left- and right-sided organs.

Renal cell carcinoma (RCC) located on the left with tumor thrombus does not have a worse prognosis than RCC located on the right [3]. In the thyroid, Gessl et al. showed that a larger proportion of both benign and malignant tumors tended to affect the right lobe [4]. However, no study has attempted to investigate differences in features between the right and left hepatic lobes. In the present study, we aimed to explore the clinical features of laterality in HCCs and consider the probability of the predictable power for the prognosis in preoperative factors.

\section{Materials and methods}

This retrospective single-center study was conducted between April 2000 and 2018. All patients undergoing liver resection for the first time for a single tumor located within the right lobe or left lobe, and who had been diagnosed pathologically as having HCC were enrolled. Essentially, the left lobe of the liver is divided to the left by the middle hepatic vein whereas the right lobe is defined as the portion of the liver to the right side of the middle hepatic vein $[1,2]$. On the basis of this, as the definition showed below, we divided the eligible patients into two groups based on the location of the tumor in the liver: a right-sided group (RSG), whose tumors were located within the right lobe, and a left-sided group (LSG), whose tumors were located within the left lobe. We excluded the tumor which had expanded to both lobes, multiple HCCs, or lesions in the caudate lobe.

All data were collected retrospectively by using medical chart review. We investigated the gender, ages, and physical features of the patients in both groups, including pathological findings in the liver. The collected clinical data included the preoperative retention rate of indocyanine green at $15 \mathrm{~min}$ (ICGR15), the alpha fetoprotein (AFP) level, and the level of protein induced by vitamin $K$ absence or antagonists-II (PIVKA2). In principle, at our center, anatomical (AR) or nonanatomical (NAR) liver resection is performed in accordance with the Makuuchi criteria [5-8]. Therefore, in both groups of patients, the types of operations were classified for comparison. In this study, we excluded laparoscopic surgery and liver transplant throughout our observation periods.

The operation time and total amount of blood loss were recorded. Based on pathological findings, the differences in tumor size and total tumor volume were recorded, and we investigated whether or not the tumors had invaded the portal vein, hepatic vein, or bile duct. Specifically, we recorded the incidence of hepatic vein invasion or thrombus (vv), portal vein invasion or thrombus (vp), hepatic artery invasion or thrombus (va), or biliary duct or thrombus (b). Moreover, the tumor's growth pattern was evaluated (expansive growth (EG) or invasive growth (IG)), and the data were compared between the two groups.

Patients visited the hospital once a month for the first 12 months after surgery and at 2- to 3-month intervals thereafter. Tumor markers, including AFP and PIVKA2, were examined at each visit. Patients were monitored by contrast-enhanced computed tomography of the chest and abdomen at 3-month intervals for the first 12 months and at 4-month intervals thereafter. During the follow-up, re-hepatectomy was performed for the patients who were detected under three numbers of recurrent lesions. Patients who were not eligible as the curative operation were planned to perform chemotherapy, transcatheter arterial chemoembolization (TACE), or best supportive care. We excluded the patients who were lost follow-up from this study. We also examined postoperative complications in terms of the number of patients whose postoperative ascites was more than $1000 \mathrm{ml}$ and the figure for patients with pleural effusion requiring thoracentesis. We investigated patients' prognosis using Kaplan-Meier analysis and log-rank test for comparison of overall survival (OS) and relapse-free survival (RFS). Secondly, we examined the cumulative number of patients with hematogenous metastatic lesions and recurrent lesions in the liver after curative resection. The date of recurrence was defined as the first examination date when recurrence was observed by imaging modalities, including ultrasound, computed tomography (CT), magnetic resonance imaging (MRI), and angiography. Furthermore, univariate analysis was performed using the Cox proportional hazards model to detect the clinical characteristics that were correlated with OS and RFS. Then, multivariate analysis was carried out to evaluate statistically any differences in laterality among several preoperative factors for which significant differences were demonstrated by univariate analysis.

\section{Definition}

We defined RSG as the single tumor of HCC that existed at the right side of the middle hepatic vein in the liver. Meanwhile, LSG was the single tumor of HCC that existed at the left side of the middle hepatic vein $[1,2]$. More specifically, the tumor of segments 5, 6, 7, and 8 in the right lobe of the liver was considered as RSG and segments 2, 3, and 4 in the left lobe of the liver was LSG.

\section{Statistical analysis}

All data were analyzed using the SPSS statistical software package (Ver 25.0; SPSS Inc., Chicago, IL, USA). Survival was estimated using the Kaplan-Meier method, and survival estimates were compared using the log-rank test. Data were censored on July 1, 2018. Patients who were lost to follow-up were excluded from this study to lead 
to the accurate statistical results. Patients who were alive on July 1, 2018, were censored for OS analysis. Relapsefree survival was calculated from the data at diagnosis until the date of disease recurrence or HCC-related deaths. OS was calculated from the data at diagnosis to the date of HCC-related deaths and OS outcome contained only HCC-related deaths. Continuous variables were presented as the median and range and were compared using the Mann-Whitney $U$ test. Categorical variables were compared using Fisher's exact test, and continuous variables were examined using Student's $t$ test. Univariable analyses were performed to identify the significant distinctive prognostic factors of the LSG vs the RSG using the Cox regression model. Differences at $P<0.05$ were considered statistically significant. The multivariable model was performed in preoperative factors and used to compare other predictive factors related to $\mathrm{HCC}$ prognosis that were shown to be significantly different by univariable analysis. Regression models were used to obtain hazard ratios and their confidence intervals $[9,10]$, and the proportional hazard assumption was checked for all variables. In order to evaluate interaction effect, variance, and confounding, analysis of variance (ANOVA), Brown-Forsythe, and Bartlett's tests were additionally performed.

\section{Results}

\section{Patient background}

During the study period, 947 patients were diagnosed pathologically as having HCC at Dokkyo Medical University. The tumor was situated in the right lobe in 406 patients, whereas it was situated in the left lobe in 189 . Four hundred and two patients were considered ineligible for the study because the tumor location was beyond the middle hepatic veins or multiple tumors were located in both lobes. The median age of the patients was 69 years, and there were 471 men and 124 women. The median body mass index (BMI) was 23 .

With regard to disease etiology in relation to viral infection, 119 patients were positive for hepatitis $\mathrm{B}$ virus $(\mathrm{HBV}+), 191$ were positive for hepatitis $\mathrm{C}$ virus $(\mathrm{HCV}+)$, 195 were both $\mathrm{HBV}+$ and $\mathrm{HCV}+$, and 91 had neither $\mathrm{HBV}+$ nor $\mathrm{HCV}+$. There were 15 patients with normal liver, 279 with liver cirrhosis, and 301 with chronic hepatitis. The median tumor size was $2.8 \mathrm{~cm}$. AR was performed for 334 of the patients, and NAR for 261 (Table 1).

\section{Univariate analysis of LSG and RSG}

The patients' background factors revealed significant differences in operation time between the two groups. That in the RSG was $285 \mathrm{~min}$ and that in the LSG was 250 min. However, there were no inter-group differences in clinical laboratory data or tumor markers. The amount
Table 1 Patients' background

\begin{tabular}{ll}
\hline Characteristics & Total patients $(\boldsymbol{n}=\mathbf{5 9 5})$ \\
\hline Age (year) & $21-84$ (median 69) \\
Gender (male/female) & $471 / 124$ \\
BMI & $15.3-39.2$ (median 23) \\
Disease etiology & 119 \\
HBV+ & 191 \\
HCV+ & 195 \\
HBV+ HCV+ & 91 \\
HBV- HCV- & \\
Background of liver & 15 \\
Normal liver & 301 \\
Chronic hepatitis & 279 \\
Liver cirrhosis & $0.6-40$ (median 2.8) \\
Tumor size (cm) & \\
Surgical procedure & 334 \\
AR & 261 \\
NAR &
\end{tabular}

In this study, we defined HBV positivity as positivity for any antigens and HCV positivity as positivity for antibody against HCV. Liver fibrosis grade was diagnosed on the basis of the Inuyama criteria, which classifies the background liver from fo to $\mathrm{f} 4$

$B M I$ body mass index, $H B V$ hepatitis $B$ virus, $H C V$ hepatitis $C$ virus, $A R$ anatomical resection, NAR non-anatomical resection

of blood loss and the numbers of AR and NAR also showed no significant inter-group differences. With regard to pathological findings, the median maximum tumor diameter was $28 \mathrm{~mm}$ in the RSG and $25 \mathrm{~mm}$ in the LSG $(p=0.61)$. The total tumor volume in the RSG was $11.5 \mathrm{~cm}^{3}$ and that in the LSG was $9.8 \mathrm{~cm}^{3}$. Furthermore, 66 patients had more than $1000 \mathrm{ml}$ of ascites in the RSG and 33 did so in the LSG $(p=0.65)$. There were 89 cases of pleural effusion in the RSG and 9 in the LSG, the difference being significant $(p=0.02)$. With regard to the pattern of recurrence, there were significant differences among the numbers of patients which had metastatic lesions in the lung, bone, or brain, being 29 in the RSG and 23 in the LSG ( $p=0.044)$. There was no significant inter-group difference in the number of patients with liver metastasis $(p=0.64): 236$ in the RSG and 114 in the LSG (Table 2).

\section{Overall survival and relapse-free survival}

The median OS duration was 72.6 months in the RSG and 60.2 months in the LSG $(p=0.0017$; hazard ratio 1.336; $95 \% \mathrm{Cl} 1.058-1.751)$. The RFS was 19.6 months for the RSG and 14.5 months for the LSG ( $p=0.0401$; hazard ratio $1.269 ; 95 \% \mathrm{Cl} 1.029-1.565)$. Both $\mathrm{OS}$ and RFS were significantly shorter in the LSG. The 5-year cumulative survival rates and cumulative disease-free survival rates were $49.5 \%$ and $19.1 \%$ in the LSG and 
Table 2 Variables in the RGS and LGS

\begin{tabular}{|c|c|c|c|}
\hline Characteristic & RGS $(n=406)$ & LGS $(n=189)$ & $p$ value \\
\hline \multicolumn{4}{|l|}{ Background } \\
\hline Age & 68 & 69 & 0.12 \\
\hline Gender (male/female) & $326 / 80$ & $145 / 44$ & \\
\hline BMl & 23.9 & 24.1 & 0.89 \\
\hline \multicolumn{4}{|l|}{ Preoperative laboratory data } \\
\hline AST & $36(10-158)$ & $41(24-114)$ & 0.58 \\
\hline ALT & $31(3-183)$ & $39(13-172)$ & 0.51 \\
\hline Alb & $3.5(1.6-4.9)$ & $3.6(2.1-4.8)$ & 0.65 \\
\hline ICGR15 & $15(1-74)$ & $17.7(4-48)$ & 0.61 \\
\hline РT\% & $83(28-120)$ & $84(0.1-20)$ & 0.87 \\
\hline AFP & 21 & 15 & 0.11 \\
\hline PIVKA2 & 46 & 45 & 0.86 \\
\hline \multicolumn{4}{|l|}{ Operative findings } \\
\hline Operation time (min) & 285 & 250 & 0.0024 \\
\hline Bleeding (ml) & 497 & 468 & 0.39 \\
\hline \multicolumn{4}{|l|}{ Pathological findings } \\
\hline Tumor size (mm) & 28 & 25 & 0.61 \\
\hline Total tumor volume & 11.5 & 9.8 & 0.62 \\
\hline$v v+(n=)$ & 16 & 10 & 0.46 \\
\hline $\mathrm{vp}+(n=)$ & 108 & 52 & 0.83 \\
\hline $\mathrm{va}+(n=)$ & 2 & 2 & 0.43 \\
\hline$b+(n=)$ & 7 & 7 & 0.16 \\
\hline IG & 39 & 24 & 0.26 \\
\hline EG & 367 & 165 & 0.18 \\
\hline \multicolumn{4}{|l|}{ Postoperative course } \\
\hline Ascites > $1000(n=)$ & 66 & 33 & 0.65 \\
\hline Pleural effusion ( $n=)$ & 89 & 9 & 0.02 \\
\hline \multicolumn{4}{|l|}{ Mode of operation } \\
\hline Anatomical resection & 229 & 105 & 0.87 \\
\hline Lobectomy & 12 & 28 & $<0.0001$ \\
\hline Sectionectomy & 34 & 43 & $<0.0001$ \\
\hline Segmentectomy & 142 & $※$ & - \\
\hline Non-anatomical resection & - & - & - \\
\hline Partial resection & 177 & 84 & 0.83 \\
\hline \multicolumn{4}{|l|}{ Pattern of recurrence } \\
\hline Hematogenous metastasis & 29 & 23 & 0.044 \\
\hline Intra hepatic metastasis & 236 & 114 & 0.64 \\
\hline Local recurrence & 79 & 32 & 0.47 \\
\hline Distant inside the liver & 157 & 82 & 0.26 \\
\hline
\end{tabular}

Sectionectomy was defined as lateral, median, anterior, and posterior hepatic resection. Segmentectomy means segment $5,6,7$, and 8 resection. $*$ Because segment 4 resection was considered as median hepatic resection, segmentectomy in LGS was not applicable as shown. As for pattern of recurrence, local recurrence was defined as recurrent tumor located within the right lobe in RGS or the left lobe in LGS. This included single and multiple recurrent tumors AST aspartate aminotransferase, ALT alanine aminotransferase, Alb albumin, ICGR15 indocyanine green retention rate at $15 \mathrm{~min}$, PT\% prothrombin time and international normalized ratio, AFP alpha fetoprotein, PIVKA2 protein induced by vitamin $\mathrm{K}$ absence or antagonists-ll, $v v$ hepatic vein invasion or thrombus, $v p$ portal vein invasion or thrombus, $v a$ hepatic artery invasion or thrombus, $b$ bile duct invasion or thrombus, $E G$ expansive growth, $I G$ invasive growth 
$55.6 \%$ and $24.5 \%$ in the RSG, respectively $(p=0.026$; Figs. 1 and 2).

Univariable and multivariable analyses in overall survival Univariable analyses of OS revealed that in the LSG the following factors were prognostically significant: resection type, ICGR15, AFP, PIVKA2, tumor size, operation time, blood loss, HBV, hepatic vein invasion, and portal vein invasion. On the basis of the results of log-minuslog plot ANOVA, Brown-Forsythe, and Bartlett's tests, preoperative significant predictive factors including LSG, ICGR15, AFP, PIVKA2, tumor size, and HBV did not have interaction effect and confounders, and proportional hazard was confirmed. Multivariable analysis of preoperative factors that were prognostically significant in the univariable analyses showed that the LSG, ICGR15, AFP, and tumor size were significant. More specifically, in terms of OS, the results revealed that the LSG had a significant association with (presence/absence) (HR, 1.371; 95\% CI 1.073-1.752; $p=0.012)$, ICGR (HR, 1.018; 95\% CI 1.007-1.030; $p=0.002)$, AFP $(<13$, $>13.1)$ (HR, 1.777; 95\% CI 1.384-2.282; $p<0.001$ ), and tumor size $(<5 \mathrm{~cm},>5.1 \mathrm{~cm})(\mathrm{HR}, 1.949$; $95 \%$ CI 1.470 2.582; $p<0.001$ ) (Table 3).

\section{Univariable and multivariable analyses in relapse-free survival}

Univariable analysis of RFS revealed that in the LSG the following factors were prognostically significant: resection type, ICGR15, AFP, PIVKA2, tumor size, operation time, blood loss, HBV, hepatic vein invasion, and portal vein invasion. In preoperative factors, multivariable analyses of that were prognostically significant, and the univariable analysis showed that the LSG, ICGR15, AFP, PIVKA2, and tumor size were significant. LSG was one of the significant preoperative factors similar to the results of OS (Table 4).

\section{Discussion}

The results of this study revealed that left-sided HCC had a significantly poorer outcome and a higher rate of hematogenous recurrence than right-sided HCC. Multivariable analysis showed that the laterality was one of the significant preoperative predictable factors. In this study, especially for multivariable analysis, we focused on the preoperative factors and only included simple factors. This is our firm belief that preoperative simple factors only play the beneficial role in clinical oncology and are useful to predict the patient outcomes in clinical settings.

Previous studies of HCC have revealed that the presence of vascular invasion [11], higher levels of AFP and PIVKA2 [12], the presence of hepatitis [13], a larger tumor size [10, 14], higher ICG levels and rates of liver cirhosis [15], and a higher amount of intraoperative blood loss [16-18] are strong and independent predictors of outcome. Among them, our results revealed that ICG, AFP, PIVKA2, and tumor size had predictive prognostic power as the preoperative factors (Tables 3 and 4). Earlier studies have shown that the ability of the hepatocytes to take up ICG becomes rate limiting at very

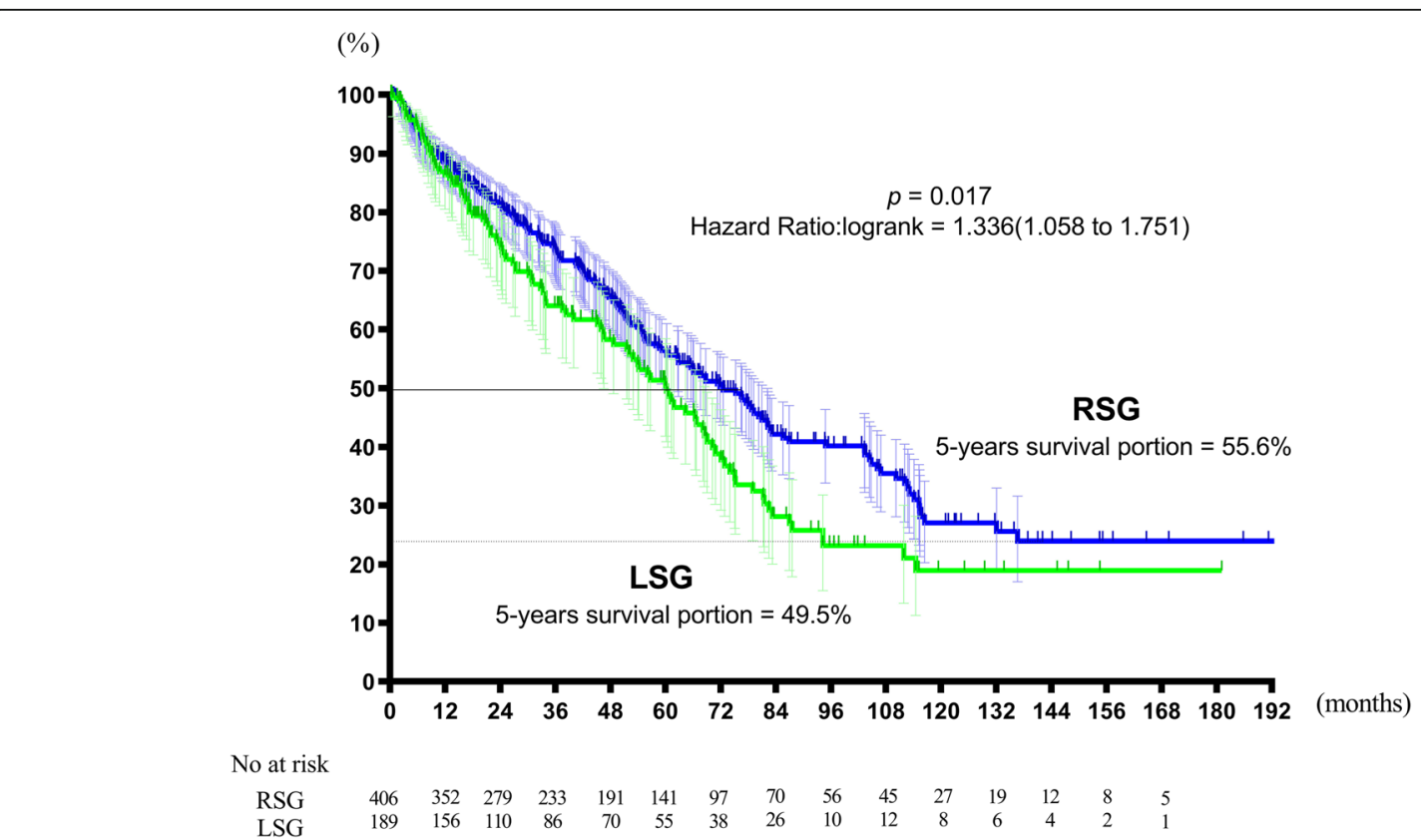

Fig. 1 Overall survival. The median OS duration was 72.6 months in the RSG and 60.2 months in the LSG ( $p=0.0017$; hazard ratio $1.336 ; 95 \% \mathrm{Cl}$ 1.058-1.751). OS was significantly shorter in the LSG. The 5 -year cumulative survival rates were $49.5 \%$ in the LSG and $55.6 \%$ in the RSG ( $p=0.017)$ 


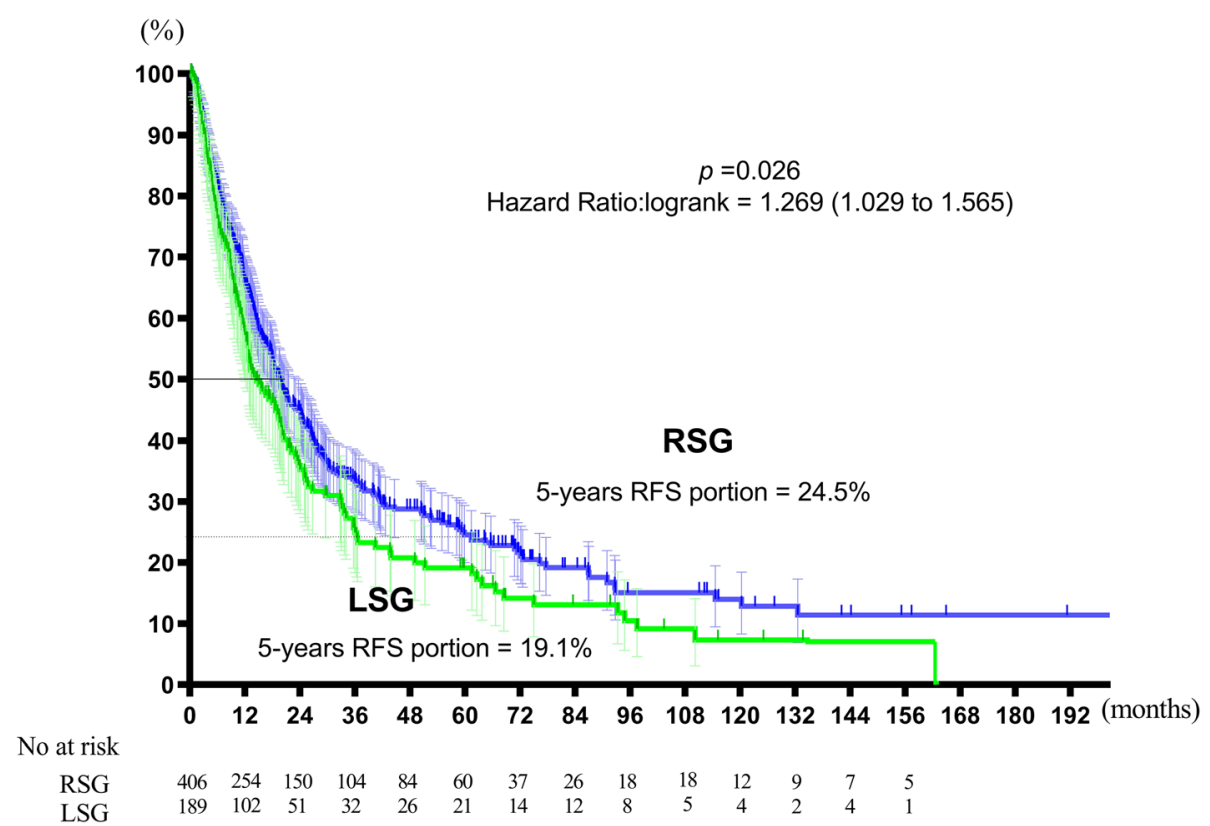

Fig. 2 Relapse-free survival. The RFS was 19.6 months for the RSG and 14.5 months for the LSG ( $p=0.0401$; hazard ratio 1.269; 95\%Cl 1.029-1.565). RFS was significantly shorter in the LSG. The 5 -year cumulative disease-free survival rates was $19.1 \%$ in the LSG and $24.5 \%$ in the RSG $(p=0.026)$

high concentrations, and ICG clearance (ICG-K) under these circumstances represents a sensitive measure of liver cell function [19]. Several reports revealed ICG can predict accurate liver function. In our department, we made surgical procedure on the basis of the level of ICT test. Anatomical resection, which had the better prognostic result as shown in Table 3, only undertook for the patients who had the lower level of ICG. We considered this is the reason why our results showed the higher level of ICG lead to the poor prognosis. Meanwhile, AFP and PIVKA2 are reliable markers to predict patient outcomes reflecting tumor biology. These markers are also useful to detect recurrence after curative resection [20]. In relation to tumor size, it is an important factor to estimate stage. Huang et al. reported that it is the most important determinant of RFS and OS in resected 230 primary-stage I HCC patients [21]. Moreover, Goh et al. also revealed that the tumor size is one of the independent prognostic factors of RFS for solitary HCC after LR in $560 \mathrm{HCC}$ patients [22].

In addition to these well-known factors, one previous study found that left-sided partial liver resections were associated with poorer outcomes [23]. However, that study explored only partial resection in a small number of cases. In contrast, the present study was performed with a far larger number of patients and included several types of operations, although similar results and associations with left-sided tumor resection were found. Moreover, multivariate analysis revealed that left-sided resection was one of the significant predictive factors of OS when we focused on preoperative factors.
In general, the right lobe is larger than the left lobe. This partly accounts for the fact that a larger proportion of HCCs are located on the right side. Despite this, our results illustrate that HCCs located in the left lobe have a poor prognosis and show a higher frequency of hematogenous metastasis. We consider that there are two major reasons for this.

One possible reason for the higher HCC recurrence with left-sided resection is the larger size of the liver remnant. HCC develops according to the background of the underlying chronic liver disease, such as cirrhosis or viral hepatitis. Larger liver remnants such as those resulting from left-sided liver resection include larger amounts of liver tissue, with a risk of future HCC development. Furthermore, the present univariable analysis illustrated that a higher ICG retention rate contributed to poorer overall survival. This could possibly mean that remnant liver with a poorer tissue background might tend to have a higher frequency of recurrent HCC.

Another potential explanation could be the resection margin. Previous studies have revealed that the resection margin may be a vital factor that influences the recurrence rate [24-26]. As mentioned above, the left lobe of the liver is smaller than the right lobe. Thus, the margin after left-sided resection may be smaller than that after right-sided resection, thus leading to a poorer outcome.

To our knowledge, clinical outcomes of HCC patients have not been studied previously in relation to the surgical site in terms of left-sided versus right-sided resection. Our study is the first to explore differences in patient 
Table 3 Associations between cumulative death proportions and clinical factors demonstrated by univariable and multivariable analyses

\begin{tabular}{|c|c|c|c|c|c|c|c|c|}
\hline & & \multicolumn{3}{|c|}{ Univariable analysis } & \multicolumn{4}{|c|}{ Multivariable analysis (only preoperative factors) } \\
\hline & & HR & $95 \% \mathrm{Cl}$ & $p$ value & HR & $95 \% \mathrm{Cl}$ & & $p$ value $^{a}$ \\
\hline Age & Continuous & 1.018 & $1.004-1.031$ & 0.010 & 1.018 & $1.002-1.033$ & & 0.019 \\
\hline \multirow[t]{2}{*}{ Sex } & Female & Ref & & & Ref & & & \\
\hline & Male & 0.844 & $0.642-1.109$ & 0.220 & 1.049 & $0.785-1.402$ & & 0.745 \\
\hline \multirow[t]{2}{*}{ Location } & RGS & Ref & & & Ref & & & \\
\hline & LGS & 1.34 & $1.055-1.702$ & 0.018 & 1.371 & $1.073-1.752$ & & 0.012 \\
\hline \multirow[t]{2}{*}{ Resection type } & Anatomical resection & Ref & & & Ref & & & \\
\hline & Non-anatomical resection & 1.407 & $1.119-1.768$ & 0.003 & - & - & - & - \\
\hline ICGR & Continuous & 1.019 & $1.008-1.03$ & 0.001 & 1.018 & $1.007-1.030$ & & 0.002 \\
\hline \multirow[t]{2}{*}{ AFP, ng/mL } & $<13$ & Ref & & & & & & \\
\hline & $>13.1$ & 1.804 & $1.413-2.302$ & $<0.001$ & 1.777 & $1.384-2.282$ & & $<0.001$ \\
\hline \multirow[t]{2}{*}{ PIVKA2, ng/mL } & $<40$ & Ref & & & & & & \\
\hline & $>41$ & 1.597 & $1.267-2.012$ & $<0.001$ & 1.256 & $0.972-1.623$ & & 0.082 \\
\hline \multirow[t]{2}{*}{ Tumor size, cm } & $<5$ & Ref & & & & & & \\
\hline & $>5.1$ & 2.134 & $1.647-2.766$ & $<0.001$ & 1.949 & $1.470-2.582$ & & $<0.001$ \\
\hline \multirow[t]{2}{*}{ Operative time, min } & $<270$ & Ref & - & & & & & \\
\hline & $>271$ & 1.708 & $1.350-2.162$ & $<0.001$ & - & - & - & - \\
\hline \multirow[t]{2}{*}{ Blood loss, ml } & $<300$ & Ref & - & & & & & \\
\hline & $>301$ & 1.590 & $1.216-2.079$ & 0.001 & - & - & - & - \\
\hline \multirow[t]{2}{*}{ HBV } & Negative & Ref & - & & & & & \\
\hline & Positive & 0.697 & $0.487-0.998$ & 0.049 & 0.943 & $0.635-1.400$ & & 0.771 \\
\hline \multirow[t]{2}{*}{$\mathrm{HCV}$} & Negative & Ref & - & & & & & \\
\hline & Positive & 1.083 & $0.850-1.380$ & 0.518 & - & - & - & - \\
\hline \multirow[t]{2}{*}{ Hepatic vein invasion } & Negative & Ref & - & & & & & \\
\hline & Positive & 2.180 & $1.350-3.518$ & 0.001 & - & - & - & - \\
\hline \multirow[t]{2}{*}{ Portal vein invasion } & Negative & Ref & - & & & & & \\
\hline & Positive & 1.705 & $1.340-2.171$ & $<0.001$ & - & - & - & - \\
\hline
\end{tabular}

$H R$ hazard ratios, $95 \% \mathrm{Cl} 95 \%$ confidence interval

anput criteria for multiple analysis were preoperative factors with $p<0.05$ in univariate analysis with age and sex

outcome according to tumor location. Nevertheless, this study had some limitations. It was retrospective in design, which limited our ability to obtain certain types of data. However, our primary outcome variable was HCC recurrence, and our primary predictor variable was leftsided versus right-sided resection, which are both objective and readily available data. Moreover, this study focused on preoperative factors in terms of prediction for prognosis. Laterality might not keep the statistical significance if we put all clinical factors randomly. Again, this is our firm belief that preoperative factors only have significance to project patient outcomes in clinical settings. For this reason, we put only preoperative factors which had significant difference in univariable analyses into multivariable analysis.
Other limitations were the single-center design and small sample size. The vast majority of our patients had viral hepatitis, and therefore, our results may not be generalizable to HCC patients with non-viral liver disease and those with non-alcoholic steatohepatitis (NASH) [27]. Additionally, all of the patients were Asian, which limits the application of our conclusions to other ethnic groups. However, our study included well-defined consecutive HCC patients undergoing hepatectomy at a university medical center.

\section{Conclusions}

The LSG had a poorer outcome than the RSG. Our results showed that tumor laterality is a significant preoperative factor affecting the outcome of HCC. To our 
Table 4 Associations between relapse-free survival proportions and clinical factors demonstrated by univariable and multivariable analyses

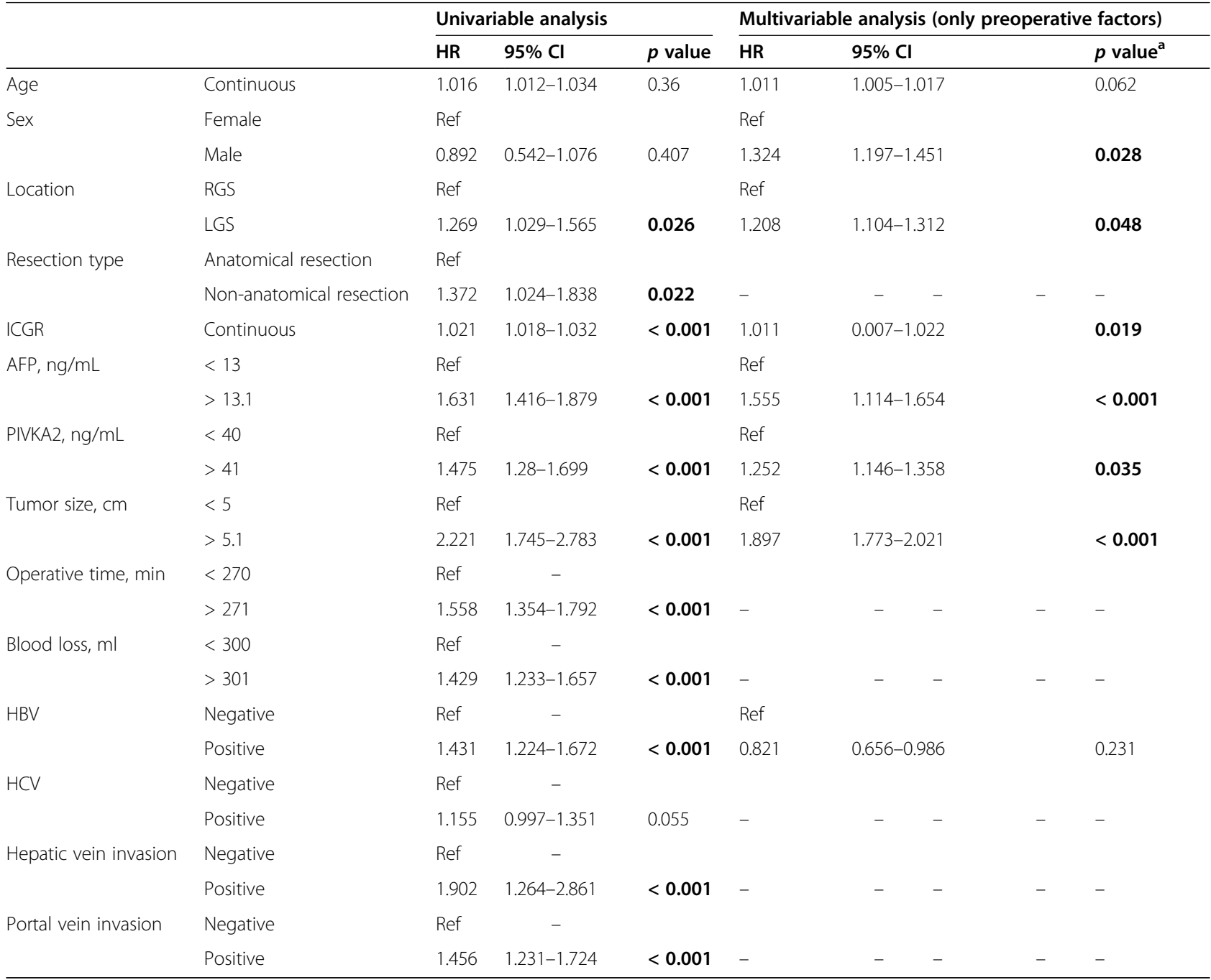

HR hazard ratios, $95 \% \mathrm{Cl} 95 \%$ confidence interval

anput criteria for multiple analysis were preoperative factors with $p<0.05$ in univariate analysis with age and sex

knowledge, this is the first study to have compared the prognosis of HCC between left-sided and right-sided resections. Our results show that laterality is an important preoperative variable predictive of outcome in patients with HCC. Clinicians need to be aware of this factor because laterality is a very basic variable that is easy to determine.

\section{Abbreviations}

AFP: Alpha fetoprotein; AR: Anatomical resection; b: Bile duct invasion or thrombus; CT: Computed tomography; EG: Expansive growth; HBV: Hepatitis B virus; HCC: Hepatocellular carcinoma; HCV: Hepatitis C virus; IG: Invasive growth; ICGR15: Indocyanine green retention rate at 15 min; LSG: Left-sided group; MRI: Magnetic resonance imaging; NAR: Non-anatomical resection; OS: Overall survival; PIVKA2: Protein induced by vitamin $\mathrm{K}$ absence or antagonists-II; RCC: Renal cell carcinoma; RFS: Relapse-free survival; RSG: Right-sided group; TACE: Transcatheter arterial chemoembolization; TNM: Tumor, lymph node, metastasis staging system; vab: Hepatic artery invasion or thrombus; vp: Portal vein invasion or thrombus; vv: Hepatic vein invasion or thrombus

\section{Acknowledgements}

I cannot express enough thanks to all members in our hospital for their continued support and encouragement. I offer my sincere appreciation for the learning opportunities provided by my department. My completion of this project could not have been accomplished without the support of all members of our institution.

\section{Authors' contributions}

All operations in this study were carried out by Dr. TM, Dr. TShiraki, Dr. SM, Dr. YI, and Prof. TA. Most of them were performed by Prof. KK. In addition, they played the main role to explore and consider the results. GT, TShimizu, $\mathrm{KT}$, and KHP collected and analyzed our data accurately, leading to the results. All authors read the final version of the manuscript and approved submission.

\section{Funding}

We did not have funding for this study.

\section{Availability of data and materials}

We will provide all data and material which were used for this study in accordance with requirement from readers. 


\section{Ethics approval and consent to participate}

The study protocol was approved by the institutional review boards of Dokkyo Medical University.

\section{Consent for publication}

We obtained consent for publication with signatures in the official documents approved by our ethics panel.

\section{Competing interests}

There were no competing interests.

\section{Received: 6 May 2020 Accepted: 27 November 2020}

Published online: 03 December 2020

\section{References}

1. Couinaud C. The anatomy of the liver. Ann Ital Chir. 1992; 63: 693-697. French.

2. Lange JF, Ophof PJ, Terpstra OT, de Jong KP. Functional anatomy of the liver according to Couinaud: practical guidelines. Ned Tijdschr Geneeskd. 1989:133:2377-81.

3. Thiel DD, Lohse CM, Arnold ML, Cheville JC, et al. Does left side renal cell carcinoma (RCC) with renal vein/vena cava thrombus predict worse prognosis than equivalent right side RCC tumor thrombus? Int Urol Nephrol. 2012;44:1005-12.

4. Gessl A, Raber W, Staudenherz A, Becherer A, et al. Higher frequency of thyroid tumors in the right lobe. Endocr Pathol. 2010:21:186-9.

5. Makuuchi M, Imamura H, Sugawara Y, Takayama T. Progress in surgical treatment of hepatocellular carcinoma. Oncology. 2002;62:74-81.

6. Torzilli G, Minagawa M, Takayama T, Inoue K, et al. Accurate preoperative evaluation of liver mass lesions without fine-needle biopsy. Hepatology. 1999:30:889-93.

7. Makuuchi M, Takayama T, Kubota K, Kimura W, et al. Hepatic resection for hepatocellular carcinoma-Japanese experience. Hepatogastroenterology. 1998:45:1267-74

8. Seyama Y, Kokudo N. Assessment of liver function for safe hepatic resection. Hepatol Res. 2009;39:107-16.

9. Spruance S, Reid JE, Grace M, Samore M. Hazard ratio in clinical trials. Antimicrobial Agents Chemother. 2004;48:2787-92.

10. Lim C, Mise Y, Sakamoto Y, Yamamoto S, et al. Above $5 \mathrm{~cm}$, size does not matter anymore in patients with hepatocellular carcinoma. World J Surg. 2014:38:2910-8.

11. Wang H, Wu MC, Cong WM. Microvascular invasion predicts a poor prognosis of solitary hepatocellular carcinoma up to $2 \mathrm{~cm}$ based on propensity score matching analysis. Hepatol Res. 2018;16.

12. Toyoda H, Kumada T, Tada T, Sone Y, et al. Tumor markers for hepatocellular carcinoma: simple and significant predictors of outcome in patients with HCC. Liver Cancer. 2015;4:126-36.

13. Chiu CC, Wang JJ, Chen YS, Chen JJ, et al. Trends and predictors of outcomes after surgery for hepatocellular carcinoma: a nationwide population-based study in Taiwan. Eur J Surg Oncol. 2015:41:1170-8

14. Yip VS, Gomez D, Tan CY, Staettner S, et al. Tumour size and differentiation predict survival after liver resection for hepatocellular carcinoma arising from non-cirrhotic and non-fibrotic liver: a case-controlled study. Int I Surg. 2013;11:1078-82.

15. Mizuguchi T, Kawamoto M, Meguro M, Nakamura Y, et al. Prognosis and predictors of surgical complications in hepatocellular carcinoma patients with or without cirrhosis after hepatectomy. World J Surg. 2013;37:1379-87.

16. Chikamoto A, Beppu T, Masuda T, Otao R, et al. Amount of operative blood loss affects the long-term outcome after liver resection for hepatocellular carcinoma. Hepatogastroenterology. 2012;59:1213-6.

17. Liu B, Teng F, Fu H, Guo WY, et al. Excessive intraoperative blood loss independently predicts recurrence of hepatocellular carcinoma after liver transplantation. BMC Gastroenterol. 2015;15:138.

18. Katz SC, Shia J, Liau KH, Gonen M, et al. Operative blood loss independently predicts recurrence and survival after resection of hepatocellular carcinoma. Ann Surg. 2009;249:617-23.

19. Paumgartner $G$, Probst $P$, Kraines $R$, Leevy $C M$. Kinetics of indocyanin green removal from the blood. Ann N Y Acad Sci. 1972:170:134-47.

20. Kim DY, Paik YH, Ahn SH, Youn YJ, et al. PIVKA-Il is a useful tumor marker for recurrent hepatocellular carcinoma after surgical resection. Oncology. 2007: $52-7$.
21. Huang $W-J$, Jeng $Y-M$, Lai H-S, Sheu F-YB, et al. Tumor size is a major determinant of prognosis of resected stage I hepatocellular carcinoma. Langenbecks Arch Surg. 2015:725-34.

22. Brian K P Goh, Jin-Yao Teo, Chung-Yip Chan, Ser-Yee Lee, et al. Importance of tumor size as a prognostic factor after partial liver resection for solitary hepatocellular carcinoma: Implications on the current AJCC staging system. J Surg Oncol. 2016;113:89-93.

23. Valenzuela A, Ha NB, Gallo A, Bonham C, et al. Recurrent hepatocellular carcinoma and poorer overall survival in patients undergoing left-sided compared with right-sided partial hepatectomy. J Clin Gastroenterol. 2015; 49:158-64.

24. Poon RT, Fan ST, Ng IO, Wong J. Significance of resection margin in hepatectomy for hepatocellular carcinoma: a critical reappraisal. Ann Surg. 2000;231:544-51.

25. Chau GY, Lui WY, Tsay SH, King KL, et al. Prognostic significance of surgical margin in hepatocellular carcinoma resection: an analysis of 165 Childs' A patients. J Surg Oncol. 1997;66:122-6.

26. Chen MF, Hwang $T L$, Jeng $L B$, eWang $C S$, et al. Postoperative recurrence of hepatocellular carcinoma. Two hundred five consecutive patients who underwent hepatic resection in 15 years. Arch Surg. 1994;129:738-42.

27. Mair RD, Valenzuela A, Ha NB, Ayoub WS, et al. Incidence of hepatocellular carcinoma among US patients with cirrhosis of viral or nonviral etiologies. Clin Gastroenterol Hepatol. 2012;10:1412-7.

\section{Publisher's Note}

Springer Nature remains neutral with regard to jurisdictional claims in published maps and institutional affiliations.

Ready to submit your research? Choose BMC and benefit from:

- fast, convenient online submission

- thorough peer review by experienced researchers in your field

- rapid publication on acceptance

- support for research data, including large and complex data types

- gold Open Access which fosters wider collaboration and increased citations

- maximum visibility for your research: over $100 \mathrm{M}$ website views per year

At $\mathrm{BMC}$, research is always in progress.

Learn more biomedcentral.com/submissions 